\title{
Effects of S100A6 gene silencing on the biological features of eutopic endometrial stromal cells and $\beta$-catenin expression
}

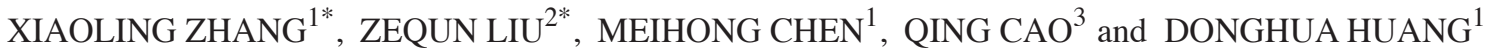 \\ ${ }^{1}$ Department of Gynecology, Jiangxi Maternal and Child Health Hospital; ${ }^{2}$ Department of Medicine, \\ Nanchang University; ${ }^{3}$ Jiangxi Province Key Laboratory of Molecular Medicine, \\ The Second Affiliated Hospital of Nanchang University, Nanchang, Jiangxi 330006, P.R. China
}

Received November 19, 2015; Accepted November 25, 2016

DOI: $10.3892 / \mathrm{mmr} .2017 .6105$

\begin{abstract}
Protein expression levels of S100 calcium binding protein A6 (S100A6) are increased in various malignancies and are associated with tumor behavior; however, the association between S100A6 and endometriosis remains to be elucidated. In order to investigate the influence of S100A6 protein, recombinant lentivirus siS100A6 was used to transfect the eutopic endometrial stromal cells. CCK-8 assay was performed to identify the proliferation ability of cell and the cell migration was detected by Transwell assay. Flow cytometry was performed to detect cell apoptosis, and western blotting and reverse transcription-quantitative polymerase chain reaction were performed to identify the expression of $\beta$-catenin. The present study investigated the role of S100A6 in endometriosis and its interaction with $\beta$-catenin by transfecting eutopic endometrial stromal cells with a recombinant lentivirus containing S100A6-specific small interfering RNA. Inhibition of S100A6 expression had a significant antiproliferative effect and reduced the migratory ability of eutopic endometrial stromal cells, and induced their apoptosis. In addition, inhibition of S100A6 expression suppressed $\beta$-catenin expression. These results suggested that inhibition of S100A6 may represent a promising novel approach for the targeted therapy of endometriosis.
\end{abstract}

\section{Introduction}

S100 calcium binding protein A6 (S100A6), which is also known as calcyclin, is a low-molecular-weight calcium-binding protein of the S100 family. S100A6 was originally purified from Ehrlich ascite tumor cells (1) and was subsequently detected in

Correspondence to: $\mathrm{Dr}$ Xiaoling Zhang, Department of Gynecology, Jiangxi Maternal and Child Health Hospital, Nanchang University, 461 Ba Yi Road, Nanchang, Jiangxi 330006, P.R. China E-mail: xlzzz777@126.com

${ }^{*}$ Contributed equally

Key words: S100 calcium binding protein A6, eutopic endometrial stromal cells, migration, proliferation, $\beta$-catenin a wide range of cell types, including epithelial cells, neurons and fibroblasts (2). S100A6 interacts with various proteins to regulate cell proliferation and differentiation, the dynamics of cytoskeletal constituents and calcium homeostasis (3). Increased expression of S100A6 has been reported in numerous malignancies, including colorectal carcinoma, osteosarcoma, pancreatic cancer and urothelial carcinoma (4-8); however, its highest expression has been observed in epithelial cells and fibroblasts (2). S100A6 has previously been demonstrated to be present in cancer tissues and is associated with tumor behavior and patient prognosis (9); however, the association between S100A6 and endometriosis remains to be fully elucidated.

Endometriosis is defined as the presence of endometrial glands and stroma within extrauterine sites, and may result in pelvic pain and infertility. It affects $\sim 10 \%$ of women of reproductive age (10). Endometriosis is not considered a malignant disorder; however, it does exhibit various characteristics similar to tumor cells, including the ability to metastasize and invade distant regions. However, the details of its etiology, pathogenesis and pathophysiology remain to be fully elucidated. It has previously been demonstrated that the Wnt/ $\beta$-catenin signaling pathway, which is involved in development, tissue self-renewal and various diseases $(11,12)$, is aberrantly activated in the endometrium of patients with endometriosis (13).

Our previous study demonstrated that S100A6 was highly expressed in eutopic endometrial stromal cells (14), and upregulated levels of S100A6 increased the expression of $\beta$-catenin; one of the most important signaling molecules in the Wnt/ $\beta$-catenin signaling pathway (15). Furthermore, inhibition of S100A6 has been reported to decrease the proliferation and invasiveness of pancreatic cancer cells in vitro (16). However, the function of S100A6 in endometriosis has yet to be fully elucidated. The present study therefore hypothesized that S100A6 may be important in the development of endometriosis via regulating the expression of $\beta$-catenin.

\section{Materials and methods}

Ethics statement. The research protocol was approved by the Consultative Committee for the Protection of People in Biomedical Research of Jiangxi Maternal and Child Health Hospital (Nanchang, China). Written informed consent was 
obtained from each patient prior to participation in the investigation.

Cell culture and recombinant lentiviral constructs. Eutopic endometrial stromal cells were derived from the endometrial tissue of 20 female patients ( 8 proliferative phase and 12 secretory phase cases) with ovarian endometriosis (mean age, $43.6 \pm 3.2$ years) that presented at the Jiangxi Province Key Laboratory of Molecular Medicine (Nanchang, China). The patients had not received any prior hormone therapy or chemotherapy. A section of each endometrial specimen was submitted for histological diagnosis and the remainder was frozen in liquid nitrogen and later prepared for use in subsequent experiments.

Cells were cultivated in Dulbecco's modified Eagle's medium (DMEM)/F12 medium (Thermo Fisher Scientific, Inc., Waltham, MA, USA) supplemented with $10 \%$ fetal bovine serum (FBS; Thermo Fisher Scientific, Inc.) and incubated at $37^{\circ} \mathrm{C}$ in a humidified atmosphere containing $5 \% \mathrm{CO}_{2}$. Experimental recombinant lentivirus [small interfering RNA (si)S100A6-enhanced green fluorescent protein (EGFP)-specific] and control recombinant lentivirus (without siS100A6) vectors were purchased from Shanghai GenePharma Co., Ltd. (Shanghai, China). EGFP was included as a reporter gene. The interference fragment sequence used for S100A6 siRNA was 5'-AAGCTGCAGGATGCTGAAATT-3', based on previous research findings (17).

siRNA transfection with lentiviruses. Eutopic endometrial stromal cells were seeded in 6-well plates and grown to $60-70 \%$ confluence. Cells were then transfected with the control recombinant lentivirus vector (Lv-control), siS100A6 lentivirus vector (Lv-siS100A6), or with no vector (untreated control) using Polybrene ${ }^{\circledR}$ reagent (Sigma-Aldrich; Merck Millipore, Darmstadt, Germany) in accordance with the manufacturer's protocol. All transfections were performed in triplicate. Transfected cells were cultured at $37^{\circ} \mathrm{C}$ in an atmosphere containing $5 \% \mathrm{CO}_{2}$ for 4 days, and were subsequently used for a range of analytical experiments.

Western blot analysis. A total of 4 days post-transfection, cells were lysed in ice-cold radioimmunoprecipitation assay buffer containing $1 \%$ protease inhibitors (Roche Diagnostics, Basel, Switzerland). Proteins were harvested and the protein concentration was determined using the Bicinchoninic Acid Protein Assay kit (Bio-Rad Laboratories, Inc., Hercules, CA, USA). Proteins $(20 \mu \mathrm{g})$ were separated by $8 \%$ SDS-PAGE and transferred to a nitrocellulose membrane (EMD Millipore, Billerica, MA, USA). Membranes were blocked for $2 \mathrm{~h}$ with $5 \%$ non-fat dried milk in Tris-buffered saline containing $0.1 \%$ Tween-20 (TBST) at room temperature, and were then incubated at $4^{\circ} \mathrm{C}$ overnight with rabbit anti-human $\beta$-catenin (1:800; cat. no. ab6302), S100A6 (1:1,000; cat. no. 181974), or $\beta$-actin $(1: 1,000$; cat. no. ab6276) primary antibodies (Abcam, Cambridge, UK). Membranes were subsequently washed three times in TBST and incubated with horseradish peroxidase-conjugated goat anti-rabbit immunoglobin $\mathrm{G}$ (1:10,000; Beijing Zhongshan Jinqiao Biotechnology Co., Ltd., Beijing, China; cat. no. ZDR-5306) for $2 \mathrm{~h}$ at room temperature. Following three washes in TBST, specific bands were detected using the enhanced chemiluminescence system (EMD Millipore). The bands were analyzed by using Gel-Pro Analyzer 4.0 software (Media Cybernetics, Inc., Rockville, MD, USA). The monoclonal anti- $\beta$-actin antibody served as an internal control for loading.

Cell proliferation assay. A total of 4 days post-transfection, cells were cultivated in 96 -well plates at a density of $3 \times 10^{3}$ cells/well in a total volume of $100 \mu \mathrm{l} /$ well. A total of $10 \mu \mathrm{l} \mathrm{Cell}$ Counting Kit-8 (CCK-8; Dojindo Molecular Technologies, Inc., Kumamoto, Japan) was added to each well when the cells reached 40-50\% confluence. The absorbance of each well was measured at a wavelength of $450 \mathrm{~nm}$ using a microtiter plate reader (Molecular Devices, LLC, Sunnyvale, CA, USA). All experiments were performed in triplicate and results are expressed as the mean \pm standard deviation.

Cell migration assay. Migration assays were conducted in modified Boyden chambers (BD Biosciences, Franklin Lakes, San Jose, CA, USA) with $8-\mu \mathrm{m}$ pore filter inserts in 24 -well plates. A total of 4 days post-transfection, $2 \times 10^{4}$ cells suspended in serum-free DMEM/F12 were added to the upper chamber. DMEM/F12 supplemented with $20 \%$ FBS was added to the lower chamber as a chemoattractant. Following a $48 \mathrm{~h}$ cultivation at $37^{\circ} \mathrm{C}$, the membrane containing migrated cells was fixed using methanol and stained with crystal violet. Migration was detected by light microscopy following removal of the non-filtered cells on the upper side of the membrane with cotton swabs. Three independent experiments were performed.

Cell apoptosis assay. A total of 4 days post-transfection, cells were harvested, diluted to a concentration of $3 \times 10^{5}$ cells $/ \mathrm{ml}$, and washed twice with ice-cold phosphate-buffered saline. Subsequently, the cells were incubated in the dark, at room temperature for 15 min with phycoerythrin (PE) Annexin $\mathrm{V}$ and 7-aminoactinomycin D (7-AAD) and $380 \mu \mathrm{l} 1 \mathrm{X}$ binding buffer from the Annexin V-PE/7-AAD apoptosis kit (Multisciences, Beijing, China) according to the manufacturer's protocol, and were analyzed by flow cytometry. Cells undergoing early apoptosis only bound to PE Annexin V, whereas cells that bound to PE Annexin V and 7-AAD were in the late stages of, or had already undergone, apoptosis. The experiment was repeated three times.

RNA extraction and reverse transcription (RT)-semiquantitative polymerase chain reaction ( $P C R)$. A total of 4 days post-transfection, total RNA was isolated from cells grown to $70-80 \%$ confluence using TRIzol ${ }^{\circledR}$ reagent (Invitrogen; Thermo Fisher Scientific, Inc.) according to the manufacturer's protocol. Total RNA $(2 \mu \mathrm{g})$ was used for the synthesis of first-strand cDNA using First Strand cDNA Synthesis kit (Promega Corporation, Madison, WI, USA). PCR primers were designed using Primer Premier 5.0 software (Premier Biosoft International, Palo Alto, CA, USA) from reported sequences (Table I). Target gene expression was normalized to $\beta$-actin levels.

PCR reactions were performed in a $20-\mu l$ volume containing $0.5 \mu \mathrm{l}$ cDNA, $20 \mathrm{pmol}$ of each primer, $0.25 \mathrm{mM}$ of each dNTP, 1 unit Taq DNA polymerase (Promega Corporation), and the buffer supplied by the manufacturer. $\beta$-catenin amplification 


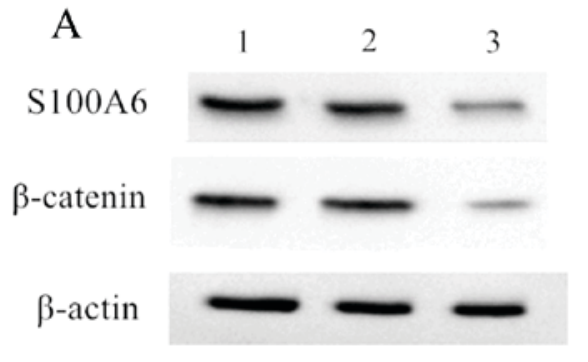

$\mathrm{C}$

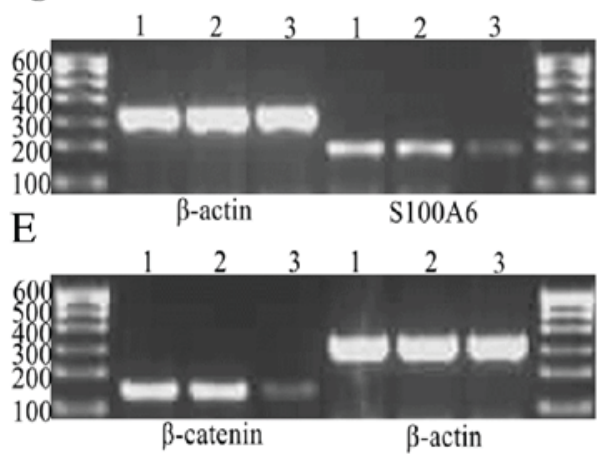

B

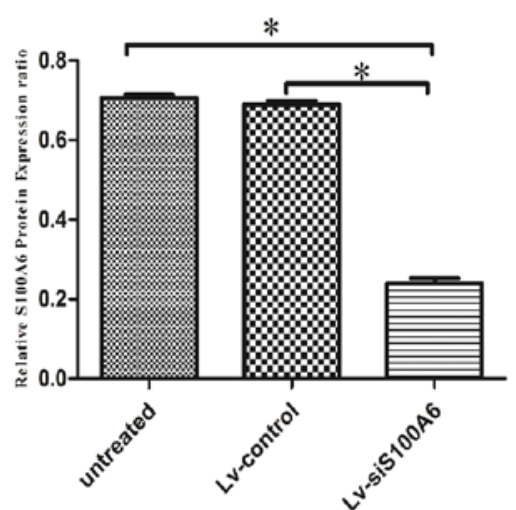

$\mathrm{D}$

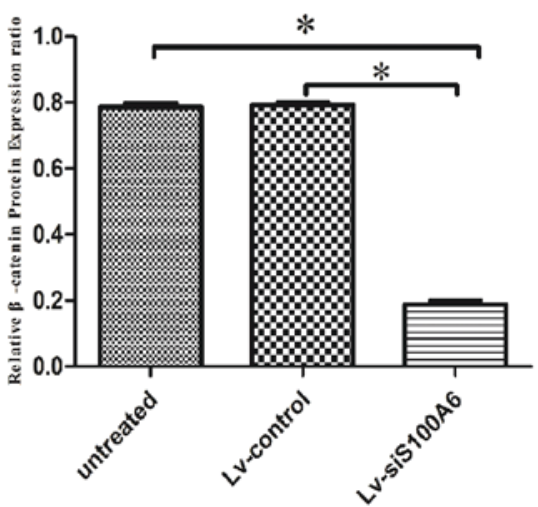

Figure 1. Silencing of S100A6 downregulated the mRNA and protein expression levels of $\beta$-catenin in eutopic endometrial stromal cells, as determined by RT-PCR and western blot analysis. (A) Western blot analysis indicated decreased S100A6 and $\beta$-catenin protein levels in eutopic endometrial stromal cells following treatment with Lv-siS100A6 compared with Lv-control. Lane 1, untreated group; lane 2, Lv-control group; lane 3, Lv-siS100A6 group. The effect of siS100A6 on S100A6 (B) protein and (C) mRNA expression, and $\beta$-catenin (D) protein and (E) mRNA expression was evaluated 4 days post-transfection by western blotting and RT-PCR, respectively. Data are presented as the mean \pm standard deviation. "P<0.05 vs. untreated and Lv-control groups. S100A6, S100 calcium binding protein A6; si, small interfering RNA; Lv-siS100A6, siS100A6 recombinant lentivirus vector; Lv-control, control recombinant lentivirus vector; RT-PCR, reverse transcription-polymerase chain reaction.

used the following thermal cycling conditions: Initial denaturation at $94^{\circ} \mathrm{C}$ for 3 min followed by 35 cycles of denaturation at $94^{\circ} \mathrm{C}$ for $30 \mathrm{sec}$, primer annealing at $53^{\circ} \mathrm{C}$ for $30 \mathrm{sec}$ and primer extension at $72^{\circ} \mathrm{C}$ for $25 \mathrm{sec}$, with a final extension at $72^{\circ} \mathrm{C}$ for $5 \mathrm{~min}$. S100A6 and $\beta$-actin amplification was similar, with the exception of an annealing temperature of $57^{\circ} \mathrm{C}$. PCR products were separated by $1.5 \%$ agarose gel electrophoresis and were subjected to densitometric scanning using an Epson photo scanner (Epson America Inc., Long Beach, CA, USA). Bands were semi-quantified using Gel-Pro Analyzer 4.0 software (Media Cybernetics, Inc., Rockville, MD, USA). All experiments were conducted in triplicate.

Statistical analysis. Data are presented as the mean \pm standard deviation. Statistical analysis was conducted using SPSS software version 19.0 (IBM SPSS, Armonk, NY, USA). Statistical analyses were performed using a one-way analysis of variance and Student's $t$-test for comparisons between two different groups, or $\chi^{2}$ test. $\mathrm{P}<0.05$ was considered to indicate a statistically significant difference.

\section{Results}

EGFP expression in eutopic endometrial stromal cells. Eutopic endometrial stromal cells were transfected with Lv-control or Lv-siS100A6. The efficiency of transfection was assessed
4 days post-transfection by analyzing EGFP expression using fluorescence microscopy, it was indicated that transfection was efficient.

Analysis of post-transfection intracellular S100A6 expression and its interrelation with $\beta$-catenin. Western blotting and RT-PCR were performed to measure intracellular S100A6 expression 4 days following the transfection of eutopic endometrial stromal cells. S100A6 protein expression was decreased in cells transfected with $\mathrm{Lv}$-siS100A6 compared with untreated and Lv-control-transfected cells, $(0.239 \pm 0.013,0.689 \pm 0.010$ and $0.706 \pm 0.008$ for Lv-siS100A6 group, untreated group and $\mathrm{Lv}$-control group, respectively; $\mathrm{P}<0.05$ ), following normalization to $\beta$-actin levels (Fig. 1A and B). There was no significant difference in the expression of S100A6 between untreated and Lv-control cells $(P>0.05)$. The mRNA expression levels of S100A6 were also lower in cells transfected with Lv-siS100A6 compared with the untreated and Lv-control-transfected cells $(\mathrm{P}<0.05$; Fig. 1C).

To further examine the interaction between S100A6 and $\beta$-catenin, the expression levels of $\beta$-catenin were detected using western blotting and RT-PCR, in cells post-transfection with Lv-siS100A6 or Lv-control constructs. As presented in Fig. $1 \mathrm{~A}$ and $\mathrm{D}, \beta$-catenin expression was significantly lower in Lv-siS100A6-transfected cells $(0.188 \pm 0.012)$ compared with Lv-control $(0.794 \pm 0.006)$ and untreated cells $(0.787 \pm 0.011)$ 
Table I. Primer sequences used for polymerase chain reaction.

Gene

S100A6

$\beta$-catenin

$\beta$-actin
Primer sequence

Product size (bp)

Sense: 5'-ACACCCTGAGCAAGAAGGAG-3'

Antisense: 5'-CCCTTGAGGGCTTCATTGTA-3'

Sense: 5'-GATTTGATGGAGTTGGACATGG-3'

Antisense: 5'-TCTTCCTCAGGATTGCCTT-3'

Sense: 5'-ATCATGTTTGAGACCTTCAACA-3'

318

S100A6, S100 calcium binding protein A6.

A

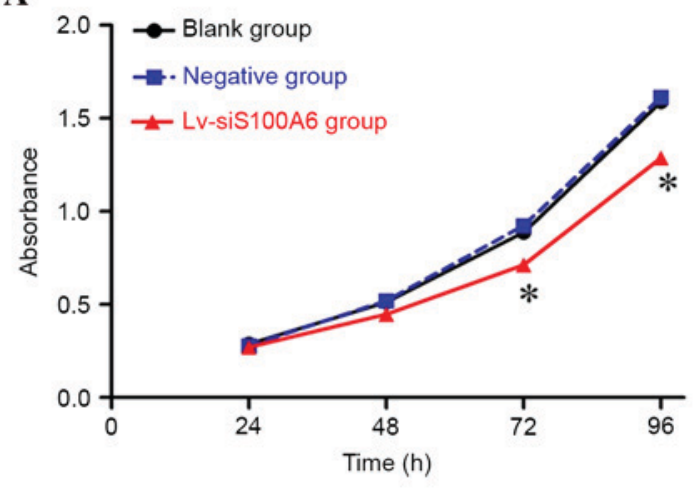

B

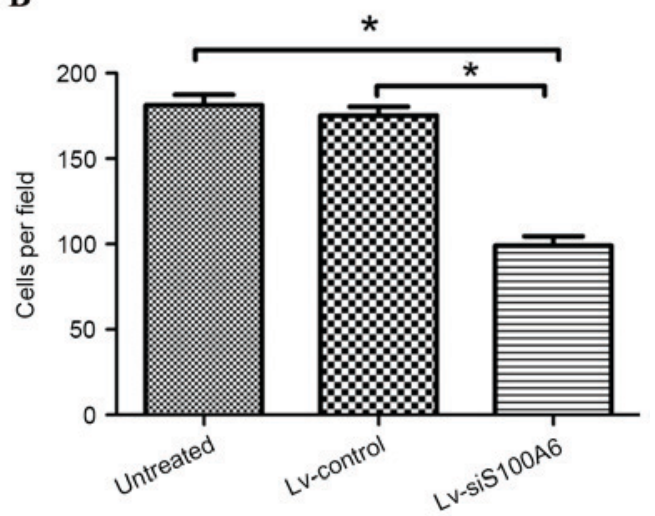

C
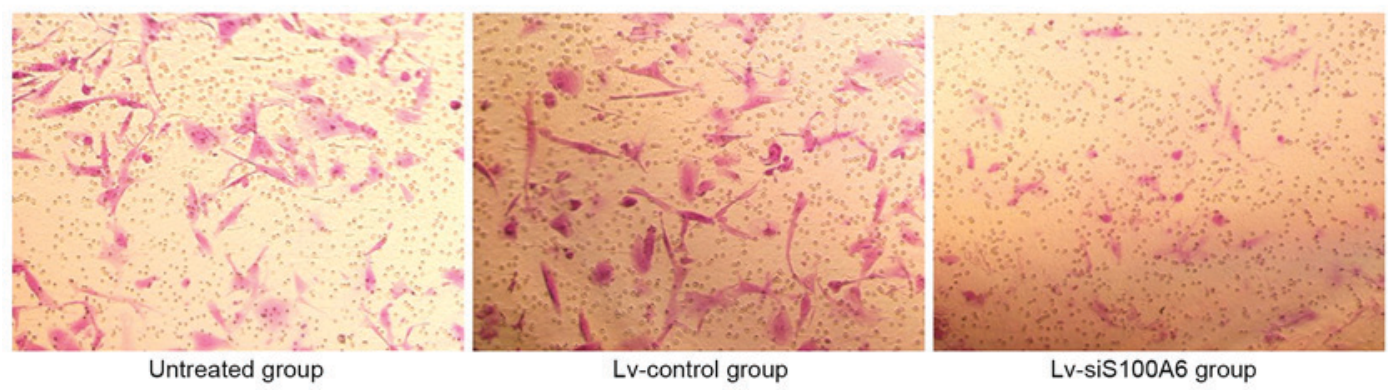

Figure 2. Silencing of S100A6 inhibited the proliferation and migration of eutopic endometrial stromal cells. (A) Proliferation of eutopic endometrial stromal cells was detected using a Cell Counting Kit-8 assay post-transfection with Lv-siS100A6. Negative group is Lv-control group. (B) Eutopic endometrial stromal cells transfected with Lv-siS100A6 or Lv-control, or untreated cells, were placed in serum-free medium and added to the upper chamber of a Transwell plate. Migratory capacity was assessed by counting the filtered cells. (C) Silencing of S100A6 markedly suppressed the number of cells that passed through the chamber (magnification, x200). Data are presented as the mean \pm standard deviation. * P<0.05 vs. untreated and Lv-control groups. S100A6, S100 calcium binding protein A6; si, small interfering RNA; Lv-siS100A6, siS100A6 recombinant lentivirus vector; Lv-control, control recombinant lentivirus vector.

following normalization to $\beta$-actin levels. In addition, $\beta$-catenin mRNA levels were observed to be markedly decreased in Lv-siS100A6-transfected cells, whereas no notable difference was detected in $\beta$-catenin levels between $\mathrm{LV}$-control and untreated cells (Fig. 1E).

siS100A6 suppresses the proliferation and migration of eutopic endometrial stromal cells in vitro. To further investigate the functional roles of S100A6 in endometriosis, the present study examined the effects of S100A6 silencing on eutopic endometrial stromal cells. As presented in Fig. 2A, the CCK- 8 proliferation assay revealed that the growth rate was significantly reduced in cells transfected with the LV-siS100A6 construct compared with untreated cells or those transfected with the Lv-control construct $(\mathrm{P}<0.05)$.

The effects of siS100A6 on the migratory capacity of eutopic endometrial stromal cells were also investigated. As presented in Fig. $2 \mathrm{~B}$ and $\mathrm{C}$, the number of migrated cells was significantly reduced in the Lv-siS100A6 group compared with the untreated group or those transfected

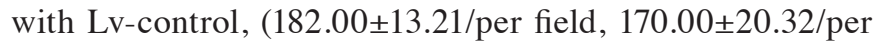
field and 96.00 $\pm 21.34 /$ per field in untreated, Lv-control-, and Lv-siS100A6-transfected cells, respectively).

siS100A6 promotes apoptosis in eutopic endometrial stromal cells in vitro. To determine whether the siS100A6-induced 
A
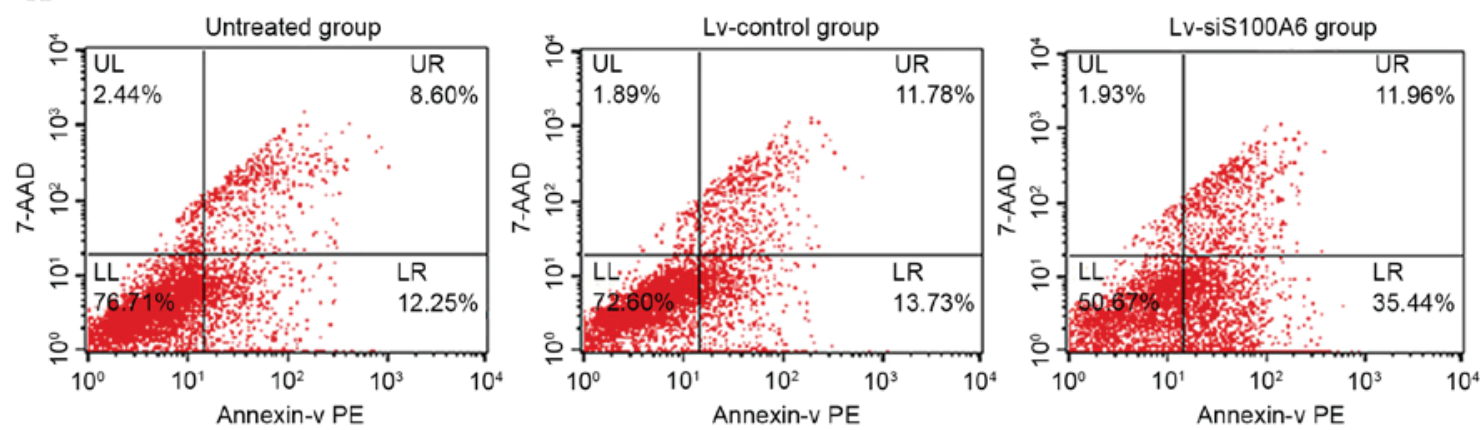

B

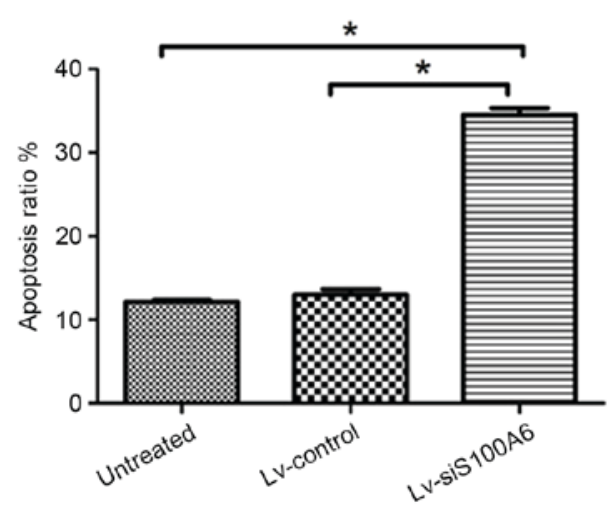

Figure 3. Eutopic endometrial stromal cell apoptotic rates were detected by flow cytometry following transfection with Lv-siS100A6. (A) Analysis of apoptosis was conducted 4 days post-transfection. Cells undergoing early apoptosis only bound to PE Annexin V, whereas cells that bound to PE Annexin $\mathrm{V}$ and 7-AAD were in the late stages, or had already undergone apoptosis. (B) Knockdown of endogenous S100A6 induced eutopic endometrial stromal cell apoptosis. The LR quadrants were used to determine apoptotic ratio. The results represent one of three experiments performed. Data are presented as the mean \pm standard deviation. ${ }^{*} \mathrm{P}<0.05$ vs. untreated and Lv-control groups. S100A6, S100 calcium binding protein A6; si, small interfering RNA; Lv-siS100A6, siS100A6 recombinant lentivirus vector; Lv-control, control recombinant lentivirus vector; PE, phycoerythrin; 7-AAD, 7-aminoactinomycin D; UL, upper left; UR, upper right; LL, lower left; LR, lower right.

inhibition of proliferation and migration may be a consequence of the induction of cell death, the present study examined the number of early apoptotic eutopic endometrial stromal cells 4 days post-transfection. Flow cytometric analysis revealed that few Lv-control-transfected (13.73\%) or untreated cells (12.25\%) underwent early apoptosis, whereas transfection with the Lv-siS100A6 construct significantly increased the percentage of early apoptotic cells to $35.44 \%$ (Fig. $3 \mathrm{~A}$ and $\mathrm{B}$; $\mathrm{P}<0.05$ ).

\section{Discussion}

S100 proteins are the largest subgroup of the EF-hand $\mathrm{Ca}^{2+}$ binding protein family, with cell- and tissue-specific expression patterns. They are multi-functional signaling proteins, which serve roles in cell growth, cell cycle progression, differentiation, transcription and secretion (18). A particular characteristic of these proteins is that individual members are localized in discrete cellular compartments, from which a few are able to relocate, upon $\mathrm{Ca}^{2+}$ activation $(19,20)$. These proteins may temporally and spatially transduce the $\mathrm{Ca}^{2+}$ signal by interacting with various specific target proteins. Notably, the majority of S100 genes are located within a gene cluster on chromosome lq21, which is a site associated with frequent chromosomal abnormalities (21).

Numerous S100 protein members have been revealed to be associated with tumor development and metastasis $(22,23)$.
Du et al (24) reported that S100P induced the dissociation of non-muscle myosin IIA filaments, leading to a weakening of focal adhesion sites and an enhancement of cell migration. Zhang et al (25) demonstrated that S100A4 regulated migration and invasion in HepG2 cells via matrix metallopeptidase (MMP) 9 signaling. MMPs are important in cell invasion and migration, and MMP2 expression was revealed to significantly increase in a p53-dependent manner following S100A14 overexpression (26). Similarly, Li et al (27) reported that MMP9 expression was upregulated following S100A6 treatment, which promoted cell proliferation, migration and tumorigenesis of HepG2.2.15 cells.

The authors of the present study previously demonstrated that S100A6 was highly expressed in eutopic endometrial stromal cells (14), and revealed that S100A6 overexpression increased the proliferation and migration of these cells, and inhibited their apoptosis (15). Endometriotic and malignant cells undergo blood vessel development and a decrease in the number of apoptotic cells (28). Spuijbroek et al (29) confirmed in vitro that the ectopic endometrium and cancer cells share an invasive ability.

In the present study, S100A6 silencing by RNA interference (RNAi) significantly inhibited the proliferation and migration of eutopic endometrial stromal cells, while promoting their apoptosis. Endometriosis was previously suggested to occur following aberrant activation of the Wnt/ $\beta$-catenin signaling 
pathway (12). Intervention of the pathway in vivo resulted in alterations in eutopic endometrial invasion and adhesion, which affected the development of endometriosis (30). Furthermore, the pathway was observed to promote eutopic endometrial cell proliferation and to improve the efficiency of eutopic endometrial implantation, invasion, metastasis and angiogenesis (30).

$\beta$-catenin is a central molecule of the Wnt $/ \beta$-catenin signaling pathway and the present study observed that its expression was decreased following S100A6 inhibition. Kilanczyk et al (31) observed that the expression of S100A6 was regulated by $\beta$-catenin in colorectal cancer cells, suggesting that the S100A6 gene may be a transcriptional target of $\beta$-catenin. In addition, reduced $\beta$-catenin levels have been reported in HepG2.2.15 cells, which result in decreased S100A6 levels (32). $\beta$-catenin binds to E-cadherin to form adherence junctions (33). Upon loss of binding with E-cadherin, unphosphorylated $\beta$-catenin accumulates in the cytoplasm and partially translocates into the nucleus, resulting in the activation of $\beta$-catenin/Tcf-mediated transcription and downstream target genes (34). Expression of these genes, including $c$-myc avian myelocytomatosis viral oncogene homolog, cyclin D and MMPs, may be responsible for cellular proliferation and migration. Furthermore, Shaco-Levy et al (35) reported the expression of MMP-2, MMP-9, E-cadherin and $\beta$-catenin in endometriosis.

In conclusion, the present study demonstrated that suppression of S100A6 expression with RNAi significantly decreased the expression levels of $\beta$-catenin, inhibited the growth and migration of eutopic endometrial stromal cells, and promoted their apoptosis. These results suggested that the multiple effects of S100A6 may be dependent on regulation of $\beta$-catenin expression via activation of the $\mathrm{Wnt} / \beta$-catenin signaling pathway. Furthermore, the results indicated that S100A6 is important in endometrial metastasis and may increase understanding regarding the precise functions of S100A6 in the promotion and progression of endometriosis. Inhibition of S100A6 may be considered a novel approach for the targeted therapy of endometriosis.

\section{Acknowledgements}

The present study was supported by the Jiangxi Provincial Natural Science Foundation of China (grant no. 20123BCB22010).

\section{References}

1. Kuźnicki J and Filipek A: Purification and properties of a novel $\mathrm{Ca} 2+$-binding protein $(10.5 \mathrm{KDa})$ from Ehrlich-ascites-tumour cells. Biochem J 247: 663-667, 1987.

2. Kuźnicki J, Kordowska J, Puzianowska M and Wozniweicz BM: Calcyclin as a marker of human epithelial cells and fibroblasts. Exp Cell Res 200: 425-430, 1992.

3. Leśniak W, Słomnicki ŁP and Filipek A: S100A6-new facts and features. Biochem Biophys Res Commun 390: 1087-1092, 2009.

4. Duan L, Wu R, Zou Z, Wang H, Ye L, Li H, Yuan S, Li X, Zha H, Sun H, et al: S100A6 stimulates proliferation and migration of colorectal carcinoma cells through activation of the MAPK pathways. Int J Oncol 44: 781-790, 2014.

5. Li Y, Wagner ER, Yan Z, Wang Z, Luther G, Jiang W, Ye J, Wei Q, Wang J, Zhao L, et al: The calcium-binding protein S100A6 accelerates human osteosarcoma growth by promoting cell proliferation and inhibiting osteogenic differentiation. Cell Physiol Biochem 37: 2375-2392, 2015.
6. Luu HH, Zhou L, Haydon RC, Deyrup AT, Montag AG, Huo D, Heck R, Heizmann CW, Peabody TD, Simon MA and He TC: Increased expression of S100A6 is associated with decreased metastasis and inhibition of cell migration and anchorage independent growth in human osteosarcoma. Cancer Lett 229: 135-148, 2005.

7. Zihao G, Jie Z, Yan L, Jing Z, Jing C, Xue L, Jing Z, Heng LW, $\mathrm{Ru} \mathrm{G}$ and Jianyu H: Analyzing S100A6 expression in endoscopic ultrasonography-guided fine-needle aspiration specimens: A promising diagnostic method of pancreatic cancer. J Clin Gastroenterol 47: 69-75, 2013.

8. Nishi M, Matsumoto K, Kobayashi M, Yanagita K, Matsumoto T, Nagashio R, Ishii D, Fujita T, Sato Y and Iwamura M: Serum expression of S100A6 is a potential detection marker in patients with urothelial carcinoma in the urinary bladder. Biomed Res 35: 351-356, 2014.

9. Zhang J, Zhang K, Jiang X and Zhang J: S100A6 as a potential serum prognostic biomarker and therapeutic target in gastric cancer. Dig Dis Sci 59: 2136-2144, 2014

10. Giudice LC and Kao LC: Endometriosis. Lancet 364: 1789-1799, 2004.

11. Clever H: Wnt/beta-catenin signaling in development and disease. Cell 127: 469-480, 2006.

12. Wend P, Holland JD, Ziebold U and Birchmeier W: Wnt signaling in stem and cancer stem cells. Semin Cell Dev Biol 21: 855-863, 2010.

13. Matsuzaki S, Darcha C, Maleysson E, Canis M and Mage G: Impaired down-regulation of E-cadherin and beta-catenin protein expression in endometrial epithelial cells in the mid-secretory endometrium of infertile patients with endometriosis. J Clin Endocrinol Metab 95: 3437-3445, 2010.

14. Xiaoling Z, Lin Q, Xiaohong Y, Huihong Z and Huai L: Expression of S100A6 in eutopic and ectopic endometrium of ovarian endometriosis patients. Chinese Journal of Practical Gynecology and Obstetrics 26: 778-780, 2010.

15. Liu Z, Zhang X, Chen M, Cao Q and Huang D: Effect of S100A6 over-expression on $\beta$-catenin in endometriosis. J Obstet Gynaecol Res 41: 1457-1462, 2015.

16. Ohuchida K, Mizumoto K, Ishikawa $\mathrm{N}$ and Tanaka M: The role of S100A6 in pancreatic cancer development and its clinical implication as a diagnostic marker and therapeutic target. Clin Cancer Res 11: 7785-7793, 2005.

17. Fuli Z, Ying Z, Yaning Z, Miao D and jian W: Influence of S100A6 siRNA on biological features of human ovarian cancer cell. Chinese Journal of Woman and Child Health Research 25: 48-51, 2014.

18. Yammani RR: S100 proteins in cartilage: Role in arthritis. Biochim Biophys Acta 1822: 600-606, 2012.

19. Van Dieck J, Brandt T, Teufel DP, Veprintsev DB, Joerger AC and Fersht AR: Molecular basis of S100 proteins interacting with the p53 homologs p63 and p73. Oncogene 29: 2024-2035, 2010.

20. Shimamoto S, Kubota Y, Tokumitsu H and Kobayashi R: S100 proteins regulate the interaction of Hsp90 with Cyclophilin 40 and FKBP52 through their tetratricopeptide repeats. FEBS Lett 584: 1119-1125, 2010.

21. Schäfer BW, Wicki R, Engelkamp D, Mattei MG and Heizmann CW: Isolation of a YAC clone covering a cluster of nine S100 genes on human chromosome lq21: Rationale for a new nomenclature of the S100 protein family. Cenomics 25: 638-643, 1995.

22. Schäfer BW and Heizmann CW: The S100 family of EF-hand calcium-binding proteins: Functions and pathology. Trends Biochem Sci 21: 134-140, 1996.

23. Saleem M, Kweon MH, Johnson JJ, Adhami VM, Elcheva I, Khan N, Bin Hafeez B, Bhat KM, Sarfaraz S, Reagan-Shaw S, et al: S100A4 accelerates tumorigenesis and invasion of human prostate cancer through the transcriptional regulation of matrix metalloproteinase 9. Proc Natl Acad Sci USA 103: 14825-14830, 2006.

24. Du M, Wang G, Ismail TM, Gross S, Fernig DG, Barraclough R and Rudland PS: S100P dissociates myosin IIA filaments and focal adhesion sites to reduce cell adhesion and enhance cell migration. J BiolChem 287: 15330-15344, 2012.

25. Zhang J, Zhang DL, Jiao XL and Dong Q: S100A4 regulates migration and invasion in hepatocellular carcinoma HepG 2 cells via NF-kB-dependent MMP-9 signal. Eur Rev Med Pharmacol Sci 17: 2372-2382, 2013

26. Chen H, Yuan Y, Zhang C, Luo A, Ding F, Ma J, Yang S, Tian Y, Tong T, Zhan Q and Liu Z: Involvement of S100A14 protein in cell invasion by affecting expression and function of matrix metalloproteinase (MMP)-2 via p53-dependent transcriptional regulation. J Biol Chem 287: 17109-17119, 2012. 
27. Li Z, Tang M, Ling B, Liu S, Zheng Y, Nie C, Yuan Z, Zhou L, Guo G, Tong A and Wei Y: Increased expression of S100A6 promotes cell proliferation and migration in human hepatocellular carcinoma. J Mol Med(Berl) 92: 291-303, 2014.

28. Swiersz LM: Role of endometriosis in cancer and tumor development. Ann N Y Acad Sci 955: 281-295, 396-406, 2002.

29. Spuijbroek MD, Dunselman GA, Menheere PP and Evers JL: Early endometriosis invades the extracellular matrix. Fertil Steril 58: 929-933, 1992.

30. Liang JY, Li CD and Zhang WY: Effects of activating and inhibiting Wnt/ $\beta$-catenin signaling pathway on murine model of eutopic endometrium and endometriosis. Zhonghua Yi Xue Za Zhi 92: 1352-1356, 2012 (In Chinese).

31. Kilańczyk E, Graczyk A, Ostrowska H, Kasacka I, Leśniak W and Filipek A: S100A6 is transcriptionally regulated by $\beta$-catenin and interacts with a novel target, lamin $\mathrm{A} / \mathrm{C}$, in colorectal cancer cell. Cell Calcium 51: 470-477, 2012.
32. Lee YT, Dimitrova YN, Schneider G, Ridenour WB Bhattacharya S, Soss SE, Caprioli RM, Filipek A and Chazin WJ: Structure of the S100A6 complex with a fragment from the c-terminal domain of Siah-1 interacting protein: A novel mode for $\mathrm{S} 100$ protein target recognition. Biochemistry 47: 10921-10932, 2008.

33. Fuchs SY, Ougolkow AV, Spiegelman VS and Minamoto T: Oncegenice beta-catenin signaling networks in colorectal cancer. Cell Cycle 4: 1522-1539, 2005.

34. Valenta T, Hausmann G and Basler K: The many faces and functions of $\beta$-catenin. EMBO J 31: 2714-2736, 2012

35. Shaco-Levy R, Sharabi S, Benharroch D, Piura B and Sion-Vardy N: Matrix metalloproteinases 2 and 9, E-cadherin, and beta-catenin expression in endometriosis, loe-grade endometrial carcinoma and non-neoplastic eutopic endometrium. Eur J Obstet Gynecol Reprod Biol 139: 226-232, 2008. 